\title{
Research on Development Patterns of Low Carbon Economy
}

\author{
Hai-ning Bai \\ Department of Economic Management \\ North China Electric Power University \\ Baoding, China
}

\begin{abstract}
At present, the world is experiencing a climate change whose main feature is warming, which has become the crisis and challenges of the world. Low-carbon economy is the best pattern which reduces greenhouse gas emission and global warming. This paper analyzes the urgency of developing low-carbon economy in China, including the pressure to reduce greenhouse gas emissions, energy security and resources and environment. On the basis of summarizing the theory and practice of low carbon economy, this paper discusses the development orientation with low-carbon development, the development way of energy-saving and pollution emission reduction and the development method using carbon neutral technology for low carbon economy, from the macro-level, meso-level and micro-level. Finally, this paper makes some measures for developing low-carbon economy in China.
\end{abstract}

Keywords: Low carbon economy; Low carbon development; Energy-saving and pollution emission reduction; Carbon neutral technology

\section{1.INTRODUCTION}

As a result of excessive consumption of fossil fuels, global warming has attracted worldwide attention. Meanwhile, global warming brought serious loss for social and economic development, deeply touched the energy security, ecological security, water safety and food safety, and even threaten the survival of mankind. Therefore, global warming caused the extreme concerns of the international community and reflection for the existing economic development model. Low carbon economic model received extensive attention of the government organization and favor $^{[1]}$. Developing and constructing low carbon economic model which solves climate warming and is environmentally friendly is not only beneficial to the transformation of the economic growth mode in China, the protection of ecological environment, the sustainable utilization of resources, and resolution of international pressure arising due to global warming, but also is the international obligations our country should undertake, and improve the international influence of major strategic initiatives.

\section{The urgency of developing low carbon economy in} China

(1) China faces huge pressure to reducing greenhouse gas emissions.

The rapid development of our country economy led the rapid growth of the demand for energy production and consumption. At present, China's greenhouse gas emissions has been ranking second in the world. Although it is not stated the specific emissions reductions for developing countries including China 2012 years ago in the "Kyoto protocol". As a responsible big country, our country must assume international obligations. Thus our country is facing the huge pressure to reduce emissions ${ }^{[2]}$.

(2) China faces a serious threat of energy security.

Energy security is an important aspect of national economic security and social security. It will directly affect the national security, sustainable development and social stability. Total energy is relatively rich in our country, but as the population size, and recoverable reserves of energy per capita is far lower than the world average. With the 
rapid development of economic society, the demand for energy is increasing. In addition, the increasing oil imports is bound to make our country's economy subject to oil exporter, also brings certain threat to China's economic security.

(3) The paranormal utilization of natural resources and ecological environment deterioration.

In recent years, our country economy keeps a high speed growth trend, resource consumption is growing fast, the ecological environment seriously damaged. At current exchange rates in 2014 China's GDP accounted for about $5.5 \%$ of world GDP. However, energy consumption reached 2.46 billion tons of standard coal which accounted for about $15 \%$ of the world's energy consumption, the cement consumption of 1.24 billion tons, accounting for $54 \%$. Resources security has become a bottleneck restricting the development of economy in our country. Strained supply of fresh water, the water crisis, inadequate supply of fresh water in many areas, has become a great obstacle for economic growth and food production.

\section{The theory connotation of low carbon economy}

The concept of "low carbon economy" was first put forward by British in the energy white paper of "Our energy future- creating a low carbon economy". The energy white paper points out that low carbon economy is requiring more economic output through the less natural resources consumption and less environmental pollution. Low carbon economy is to create a higher standard of living and the way to a better quality of life and opportunities, also for the development, application and output advanced technology created opportunities, but also can create new business opportunities and more chances of employment.

Some scholars believe that the essence of low carbon economy is energy efficiency and clean energy structure, and the core of low carbon economy is energy technology innovation and institution innovation, the aims of low carbon economy is to slow down the climate change and promote the sustainable development of human beings. Namely, relying on technological innovation and policy measures, it is necessary to implement an energy revolution, establish a less emissions of economic development mode and slow down the climate change ${ }^{[3]}$.

\section{The Development patterns of low carbon economy}

The development patterns of low carbon economy are organizing economic activity in practice through using the theory of low carbon economy. The traditional economic development mode is retrofitted to become a new type of low carbon economic model. Specifically, low carbon economic development model is a kind of green economic development model, which regards low energy consumption, low pollution, low emission and high performance, high efficiency, high benefit as the foundation, low carbon development as the development direction, energy conservation and emissions reduction as the development way, carbon neutral technology as the development method. Among them, the development direction, development way and development methods of low carbon economy respectively discusses the low carbon economy mode from the macro, meso level and micro level.

(1) The low carbon development is the development direction of low carbon economy.

The so-called low carbon development refers to maximum reduce greenhouse gas emissions under the condition of the guarantee of healthy, rapid and sustainable economic and social development. Low carbon development is a kind of more competitive, more sustainable development, which should put focus on low carbon, and the purpose of it is the development. Low carbon constraints will restrict the choice of economic development direction, decided to economic and social evolution and development in the direction of lower greenhouse gas emissions. In order to achieve the greenhouse gas emissions reduction and economic scale continuous growth of the dual goal, our country need to re-examine the existing development model, to choose a more sustained economic development model, and the low carbon economy is the first choice for achieving this goal. Thus, low-carbon development is the development direction of low carbon economy. 
(2) Energy conservation and emissions reduction is the low carbon economy development mode.

In order to realize the sustainable development of economy, reducing energy consumption and increasing the usage of renewable energy and clean energy are the main measures to reduce negative effects of energy production and consumption. The former belongs to the category of energy conservation, while the latter belongs to the category of reducing greenhouse gas emissions. In summary, in order to realize the low carbon development and sustainable development of economy, energy conservation and emissions reduction is an important way and means.

(3) Carbon neutral technology is the development method of low carbon economy.

The intergovernmental panel on climate change expert committee believe that the research scale and speed of low carbon or carbon free technology decided to the size of the future greenhouse gas emissions. Carbon neutral, this term is put forward by future forest company in 1997 in London, refers to the calculate the carbon dioxide emissions and then through afforestation (increase Carbon sinks), carbon dioxide capture and storage methods, such emissions are absorbed, in order to achieve the purpose of environmental protection.

\section{The policy and measures of low carbon economy mode in our country}

(1) Priorities to save energy and improve energy efficiency

Under the premise of improving energy efficiency, it must adhere to the principle of energy conservation priority development strategy. On the one hand, eliminate production industry and the production process. On the other hand, in the lighting equipment, household appliances, industrial motors and industrial boiler areas, it need to take a technology improvement and improve the effective use of thermal and improve the efficiency of energy conversion. Only be conducive to constantly improve the level of energy saving, can it achieve such multiple objective including keeping the energy supply security, environmental protection, and curbing greenhouse gas emissions.

(2) Make low-carbon fossil fuels and develop renewable energy

Coal based energy consumption structure is difficult to get the fundamental change in recent 10 years. This will require a carbon neutral technology. Before the consumption, the coal should be deal with the technology of low carbon or no carbonization, in order to reduce carbon emissions in the process of combustion. Under this pattern, accelerating the development of natural gas, nuclear power appropriately, vigorously developing hydro power, deeply developing wind energy, solar energy, hydro power, geothermal energy and biomass energy and other renewable energy, will be the main direction of development of low carbon economy in order to reduce the proportion of coal in energy consumption structure.

(3) Set up carbon fund and encourage researching and developing low carbon technologies

Carbon fund mainly has two forms of government funds and private funds. The former mainly depends on government funded, which mainly depends on social donations to raise funds. China has set up Clean Development Mechanism Fund and China Green Carbon Fund, which meet the financial needs of the climate change $^{[4]}$.

(4) Establish national carbon trade mechanism

In China's different functional areas, some areas are ecological barrier area, some areas are ecological benefit region. According to the international balance rules, when ecological benefit region should be in the enjoyment of the ecological benefits, it should take out to enjoy external benefits spillover reasonable share, and implement compensation for ecological protection areas.

\section{Conclusions}

Low carbon economic model received extensive attention of the government organization and favor. On the basis of summarizing the theory and practice of low carbon economy, this paper discusses the development orientation with low-carbon development, the development way of 
energy-saving and pollution emission reduction and the development method using carbon neutral technology for low carbon economy, and makes some measures for developing low-carbon economy in China.

\section{Acknowledgments}

This study was supported by the Fundamental Researc h Funds for the Central Universities (Project ID:13ZD21)

\section{References}

[1] Xing Jijun, Zhao Gang, "China Should Vigorously Develop Low Carbon Economy," Forum on Science and Technology in China, pp. 87-92, 2007.

[2] Shi Feng, Guo Chengbin, "Energy-saving in Central Heating of Architecture Projects," Applied Energy Technology, pp. 19-20, 2007.

[3] Wang Tao, Chen Lidian, "The Information from the Organization of Petroleum Exporting Countries and World Petroleum Congress Joint Workshop:the Technology to Capture and Store Carbon," World Petroleum Industry, pp.38-42, 2004.

[4] Zhang Shengdong, Song Weiming, Heyu, "Summary on the Development of International Carbon Fund," Forestry Economics, pp. 46-48, 2007. 